\title{
SAN ISIDORO DE SEVILLA: PUENTE ENTRE LA ANTIGÜEDAD Y LA EDAD MEDIA
}

\author{
Jorge Mario Cabrera Valverde
}

\begin{abstract}
RESUMEN
El artículo estudia la contribución de San Isidoro de Sevilla a la transmisión de las culturas clásica antigua y la medieval. Para ello, el autor investiga la época inmediatamente posterior a las invasiones visigóticas en España. Luego de repasar la labor ingente de estudio y de trabajo que realizó San Isidoro, se concluye que de no haber sido por mentes como la de él, la transmisión de la cultura clásica a nuestros días habría sido prácticamente imposible.
\end{abstract}

\begin{abstract}
This article studies the contribution of St. Isidore in the transmission of ancient classical and medieval cultures. The author's reaseach centers on the period of time immediately following the visigothic invasion of Spain. After reviewing St. Isidore's work and studies, he concludes that if it were not for minds like his, the transmission of classic culture to the present would have been practically impossible.
\end{abstract}

\section{Datos biográficos}

El siglo VII está representado por San Isidoro, nacido en la Bética (actual Andalucía), durante más de cincuenta años obispo de Hispalis (Sevilla) y muerto en el año 636 después de una vida de gran actividad en beneficio de su grey, de la liturgia, de los monasterios y -lo que tal vez constituye su mayor mérito- de la cultura antigua. (Prampolini 1955: 130).

San Isidoro nació alrededor del año 560. Su padre, Severiano, era de familia hispanorromana. Su madre, Teodora, probablemente era goda. Vivían en Cartagena, donde nacieron sus hermanos San Leandro, San Fulgencio y Santa Florentina. Con la invasión de los bizantinos al sudeste de España (a. 549), se trasladaron a la Bética. Muertos los padres, su hermano San Leandro, Obispo de Sevilla, se encargó de su educación. 
San Isidoro estudió y fue director de la escuela monacal de Sevilla y sucedió a su hermano en el 599. Fue Arzobispo de Sevilla durante casi 40 años, le tocó ver la conversión del rey Recaredo I (587) y la de todo el pueblo visigodo al catolicismo, en la que tuvo que ver mucho su hermano San Leandro. El III Concilio de Toledo recibió al pueblo converso (589). Años antes (585), también tuvo que ver el martirio de San Hermenegildo quien, al convertirse al catolicismo, se opuso a su padre, el rey Leovigildo, el cual permanecía en el arrianismo.

Presidió el IV Concilio de Toledo (633), el más famoso de los concilios españoles desde el punto de vista religioso y escolástico y por su importancia social y política.

\section{La escuela de Sevilla}

San Isidoro (...), artífice incansable en la obra de fusión de godos y españoles, a la vez que atiende con exquisito cuidado a la general educación de unos y otros, así del clero como del pueblo, fundando escuelas episcopales y monásticas (...), y difundiendo la vida monástica, y dando regla especial y española a sus monjes (...), escribe compendios, breviarios y resúmenes de cuantas materias pueden ejercitar el entendimiento humano. (Menéndez y Pelayo 1959: 17-8).

San Leandro colaboró mucho con el resurgimiento literario, mediando su enseñanza oral. Le preocupaba la formación de los clérigos. Ya se habían abierto las escuelas del monasterio Dumiense y del Servitano y, en Huesca, la de San Martín de Asan. Sin embargo, la de Sevilla sobrepasó a las demás, gracias al impulso de San Leandro, llegando a ser el centro de restauración científica de la España visigoda. Los alumnos aprendían a leer, estudiaban los salmos, los himnos, a Virgilio. Luego, seguía el currículo de las antiguas escuelas romanas, el trivium y el quadrivium, para que los clérigos pudieran adentrarse en la dogmática y en la exégesis de la Biblia. Estudiaban también griego y algo de hebreo.

San Isidoro se dedicó a la formación de la juventud: buscó los mejores maestros y les pagó fuertes sumas de dinero. La escuela no solo fue para Sevilla sino para toda España, y otras diócesis siguieron su ejemplo: Toledo, Mérida, Zaragoza, Palencia.

\section{La labor isidoriana}

La serie de sus obras (...) viene a constituir una inmensa enciclopedia, en que está derramado y como transfundido cuanto se sabía y podía saberse en el siglo VII, cuanto había de saberse por tres o cuatro siglos después, y, además, otras infinitas cosas, cuya memoria se perdió más adelante. (Menéndez y Pelayo 1959: 18).

San Isidoro recibió enseñanza oral y escrita. Fue muy prolífico en producción literaria. El VIII Concilio de Toledo (653) lo nombró doctor egregius. Fue hombre de amplios conocimientos: estudió tanto autores sagrados como profanos, los utilizó mucho en sus libros e incluso los citó textualmente, pues fue anotando y ordenando su material recopilado. Tomó 
notas en exégesis, teología, moral, liturgia, historia, gramática, cosmología, astronomía, física, metafísica y derecho. No es original, pero hace uso de un criterio recto al juzgar las obras. Unió el cristianismo con la literatura clásica, tomando como base las Sagradas Escrituras, y supo, sobre todo, apreciar el valor de la cultura antigua.

Un discípulo suyo, San Braulio de Zaragoza, escribe sobre él: "Después de tantas ruinas y desastres, Dios le ha suscitado en estos últimos tiempos para restaurar los monumentos de los antiguos, a fin de que no cayésemos por completo en la barbarie" ${ }^{1}$. En este sentido, San Isidoro era reconocido, ya en su tiempo, como "transmisor de la cultura clásica", especialmente romana, a la sociedad de su época.

\section{Fuentes de San Isidoro}

Ninguna ciencia humana ni divina se le ocultó (...); todas las penetró, las recorrió todas; no hubo escritor sagrado ni profano que se escondiese a su diligencia. (Menéndez y Pelayo 1959: 15).

Además de las Sagradas Escrituras, San Isidoro leyó a sus comentaristas: Orígenes, San Hilario, San Ambrosio, San Agustín, San Jerónimo, San Juan Crisóstomo y San Cipriano; entre sus contemporáneos, a San Leandro y a San Gregorio Magno; de los poetas leyó a Virgilio, Horacio, Ovidio, Persio y Lucano; de los historiadores a Eusebio y Orosio, y además a los juristas Gayo, Paulo y Teodosio.

\section{Obras de San Isidoro}

Son oeuvre profane, ses méthodes de travail, son indulgence pour la culture païenne, son goût pour la poésie antique et pour le savoir grammatical peuventils autoriser à parler d'une «Renaissance isidorienne»? (...) A juger l'oeuvre isidorienne sur ses intentions comme àses fruits, le terme de Renaissance ne semble donc pas impropre. (Fontaine, J. 1959: 863 y 865).

San Isidoro era un gran sistematizador. Sus obras fueron pensadas según un plan.

\subsection{Las "Etimologías" u "Orígenes"}

Vienen a ser los Orígenes verdadero mapa del mundo intelectual en la reducida escala que el mapa exige y con las sumarias indicaciones que las cartas geográficas toleran. Así y todo, ¿qué sería de la erudición moderna si tal libro hubiera perecido? (Menéndez y Pelayo 1959: 23).

En las "Etimologías", San Isidoro pensaba hacer una enciclopedia de todo tipo de ciencias, con ilustraciones, usando la etimología, aunque muchas veces los orígenes que atribuye a las palabras son erróneos. 
Las "Etimologías" están divididas en veinte libros, según San Braulio de Zaragoza. Los cinco primeros son una introducción. En éstos trata sobre las artes liberales (trivium y quadrivium, I a III), medicina y jurisprudencia (IV y V), los libros y oficios eclesiásticos (VI), teología y antropología (VII a XI). Los libros VII y VIII se refieren a Dios y a sus nexos con el hombre; el IX y X, al hombre y sus relaciones con el estado; el XI es de anatomía. Sigue con la descripción de animales y de la naturaleza: zoología, cosmología y geografía (libros XII a $\mathrm{XIV}$ ). Escribe también sobre edificios y campos (XV); piedras, metales, monedas, pesos y medidas (XVI); cultivo de campos y jardines (XVII); sobre guerra y juegos (XVIII); naves, edificios y vestidos (XIX); finalmente, sobre comidas, bebidas, instrumentos de casa y de campo (XX).

\subsection{Obras históricas}

Especial importancia tienen, no tanto por su espíritu crítico cuanto por su valor como fuentes, las obras de carácter histórico. (Mendoza Ruiz 1984: 120).

San Isidoro escribió tres obras del género histórico: Liber de viris illustribus, el Chronicon y una historia en dos partes: Historia de regibus Gothorum e Historia de regibus Wandalorum et Suevorum.

La primera, sobre varones ilustres, fue escrita hacia el 610; trata de complementar las obras similares de San Jerónimo y Genadio. Habla de 46 escritores, casi todos de los siglos V y VI.

El Chronicon es un resumen de las crónicas de Julio Africano, de Eusebio de Cesarea, de Víctor de Tunnuna y de algunos otros. Trata de la historia desde la Creación hasta el año 616. Siguiendo a San Agustín, la divide en seis partes, de acuerdo con los días de la Creación. San Isidoro incluye la historia de Israel, Imperios bíblicos, Grecia, Roma y algunos otros grupos o países surgidos con la caída del Imperio Romano. De Grecia toma a muchos héroes mitológicos como históricos. Habla de los bizantinos como romanos, aún después de la caída del Imperio Romano de Occidente. Al mencionar a los bárbaros, trata especialmente de los visigodos y de los vándalos. No incluye a los francos.

Al narrar la historia de los reyes godos, vándalos y suevos, San Isidoro se basa en Víctor de Tunnuna -para los vándalos- y en Hidacio -para los suevos. Lo que señala de los visigodos es de un valor histórico incalculable porque, hasta ahora, no hay otra fuente disponible, en especial para el siglo VI.

Al escribir, se muestra patriota; por ejemplo, se alegra cuando el rey Leovigildo logra el dominio de toda la Península Ibérica, y se entristece cuando los bizantinos toman la costa del sudeste. En cambio, alaba las victorias de los godos.

\subsection{Los Siete Saberes, la gramática y la dialéctica}

Mais c'est bien dans le domaine du savoir traditionnel, correspondant aux trois premiers livres des Origines, que la médiation d'Isidore entre l'Antiquité el le Moyen Age reste le plus importante et, comme telle, la plus intéressante à étudier. (Fontaine 1959: 13). 
Los tres primeros libros de las "Etimologías" eran con frecuencia separados para enseñar las siete artes liberales en la Edad Media. San Isidoro coincide mucho con Boecio y Casiodoro en estos puntos, mientras que para la retórica toma capítulos completos del $D e$ inventione de Cicerón.

El saber que ocupa el primer libro es la gramática o pericia en el hablar. Acerca de las "Etimologías", San Isidoro manifiesta: "Etimología es el origen de los vocablos; por ella se conoce muchas veces la fuerza de las palabras. Aristóteles la llamó en griego symbolos y Cicerón la llamó annotatio (anotación), porque nos da a conocer los nombres de las cosas (...). $\mathrm{Su}$ conocimiento y uso muchas veces es necesario, porque, si sabes de dónde procede un nombre, conoces mucho antes toda la fuerza del vocablo. Pues es mucho más fácil el conocimiento del objeto, conocida la etimología de su nombre" 2 .

Con respecto a la retórica, se expresa así: "es la ciencia de bien decir en los asuntos civiles para persuadir lo bueno y lo justo por abundancia de elocuencia" 3 . Brinda recomendaciones para hablar con virtud.

San Isidoro compuso otras dos obras sobre el latín: Libri differentiarum: de differentiis verborum; de differentiis rerum. El segundo es de tipo dogmático. El primero contiene observaciones filológicas y psicológicas profundas, aunque a veces en el vocabulario de voces presenta confusiones. Escribió otros glosarios o diccionarios latinos tales como los Libri glossarum Ansileubi.

De la dialéctica manifiesta que "es la disciplina ordenada a conocer las causas de las cosas. Es una parte de la filosofía que se llama lógica, esto es, racional, y se ordena a definir, investigar y diferenciar"4. Habla de los universales, de las razones primeras, de los predicamentos o categorías, de la interpretación de los silogismos (De perihermeneias), de las definiciones, de los tópicos. Cita con frecuencia a Aristóteles y a Boecio.

En el libro III, desarrolla el quadrivium. Sobre astronomía habla también en otros tratados. La geometría la resume rápidamente. Da cierta importancia a los números porque Dios lo dispuso todo "con medida, número y peso"5 y "nuestra vida está bajo la disciplina de los números cuando por ella aprendemos las horas, contamos el curso de los meses o conocemos el espacio del año que vuelve de nuevo"6. Luego, dice: "quita al tiempo el cómputo y todo queda envuelto en la ciega ignorancia"7.

\subsection{La medicina}

San Isidoro tiene un alto concepto de la ciencia médica, en la que concurren todos los saberes (...) Es notable la apreciación de san Isidoro sobre la necesidad de la investigación en medicina. (Riu, M. et al. 1935: 136).

San Isidoro tenía especial aprecio por la medicina: en el palacio arzobispal tenía una farmacia con remedios locales y de Grecia. Concebía la medicina como "la disciplina que se ordena a proteger el cuerpo o restaurar la salud; su materia son las enfermedades y las heridas. A ella pertenecen no solamente los remedios que emplean los que ejercen la medicina, que propiamente se llaman médicos, sino también la comida, bebida y manera de vestir; en una palabra todo lo que sea defensa y protección del cuerpo contra las heridas y agentes exteriores" 8 . 
Los tres primeros libros de las "Etimologías" eran con frecuencia separados para enseñar las siete artes liberales en la Edad Media. San Isidoro coincide mucho con Boecio y Casiodoro en estos puntos, mientras que para la retórica toma capítulos completos del $D e$ inventione de Cicerón.

El saber que ocupa el primer libro es la gramática o pericia en el hablar. Acerca de las "Etimologías", San Isidoro manifiesta: "Etimología es el origen de los vocablos; por ella se conoce muchas veces la fuerza de las palabras. Aristóteles la llamó en griego symbolos y Cicerón la llamó annotatio (anotación), porque nos da a conocer los nombres de las cosas (...). $\mathrm{Su}$ conocimiento y uso muchas veces es necesario, porque, si sabes de dónde procede un nombre, conoces mucho antes toda la fuerza del vocablo. Pues es mucho más fácil el conocimiento del objeto, conocida la etimología de su nombre" 2.

Con respecto a la retórica, se expresa así: "es la ciencia de bien decir en los asuntos civiles para persuadir lo bueno y lo justo por abundancia de elocuencia" 3 . Brinda recomendaciones para hablar con virtud.

San Isidoro compuso otras dos obras sobre el latín: Libri differentiarum: de differentiis verborum; de differentiis rerum. El segundo es de tipo dogmático. El primero contiene observaciones filológicas y psicológicas profundas, aunque a veces en el vocabulario de voces presenta confusiones. Escribió otros glosarios o diccionarios latinos tales como los Libri glossarum Ansileubi.

De la dialéctica manifiesta que "es la disciplina ordenada a conocer las causas de las cosas. Es una parte de la filosofía que se llama lógica, esto es, racional, y se ordena a definir, investigar y diferenciar" 4 . Habla de los universales, de las razones primeras, de los predicamentos o categorías, de la interpretación de los silogismos (De perihermeneias), de las definiciones, de los tópicos. Cita con frecuencia a Aristóteles y a Boecio.

En el libro III, desarrolla el quadrivium. Sobre astronomía habla también en otros tratados. La geometría la resume rápidamente. Da cierta importancia a los números porque Dios lo dispuso todo "con medida, número y peso"5 y "nuestra vida está bajo la disciplina de los números cuando por ella aprendemos las horas, contamos el curso de los meses o conocemos el espacio del año que vuelve de nuevo"6. Luego, dice: "quita al tiempo el cómputo y todo queda envuelto en la ciega ignorancia"7.

\subsection{La medicina}

San Isidoro tiene un alto concepto de la ciencia médica, en la que concurren todos los saberes (...) Es notable la apreciación de san Isidoro sobre la necesidad de la investigación en medicina. (Riu, M. et al. 1935: 136).

San Isidoro tenía especial aprecio por la medicina: en el palacio arzobispal tenía una farmacia con remedios locales y de Grecia. Concebía la medicina como "la disciplina que se ordena a proteger el cuerpo o restaurar la salud; su materia son las enfermedades y las heridas. A ella pertenecen no solamente los remedios que emplean los que ejercen la medicina, que propiamente se llaman médicos, sino también la comida, bebida y manera de vestir; en una palabra todo lo que sea defensa y protección del cuerpo contra las heridas y agentes exteriores" 8 . 
La doctrina que expone es tomada de Celso y de Celio Aureliano, y sus autoridades son Hipócrates y Galeno. Explica diversas enfermedades y sus tratamientos.

San Isidoro concluye "que la medicina se llama una segunda filosofía. Una y otra disciplina reclaman para sí todo el hombre, pues por la filosofía se curan las almas y por la medicina los cuerpos" 9 .

\subsection{Filosofía, antropología y cosmología}

Mais il a su s'inspirer assez de l'exemple de culture philosophique que lui laissait Augustin, et de la largeur des vues des docteurs latins du IVe siècle, pour ne pas hésiter, surtout dans les Origines, à utiliser des doctrines philosophiques encore directement païennes. (Fontaine 1959: 604).

Para San Isidoro, la filosofía es "el conocimiento de las cosas humanas y divinas, unido al ejercicio de una vida recta" 10 . La divide en tres partes: "natural, que trata del conocimiento de la naturaleza; otra, moral, que en griego se llama ética, en la que se trata de las costumbres, y la tercera, racional, en griego, lógica, en la que se busca la verdad, tanto en las cosas, como en las costumbres. La física, pues, busca la causa de las cosas; la ética, el orden en la vida, y la lógica, la razón de entender" 11.

En la física, se incluyen la antropología, la zoología, la botánica, la cosmología, la mineralogía y la geometría. Cuando trata estos temas, San Isidoro cita a San Jerónimo, San Agustín, San Ambrosio y San Clemente. En botánica, menciona a Gargilio, Marcial y Columela; en mineralogía, a Plinio el Viejo; en geografía consulta a Orosio, San Agustín, Solino y Servio. Para las etimologías sigue a Varrón. Al parecer, también se basa en una obra de Suetonio acerca de la naturaleza, que no nos ha llegado.

Siguiendo a Suetonio, San Isidoro lee filosofía griega: habla de micro y de macrocosmos (concepción estoico-platónica) y de los cuatro elementos (Aristóteles). Posiblemente es el estoico Posidonio quien "más ha influído a través de los escritores romanos en las ideas filosóficas de San Isidoro, en su antropología, en su teoría de los vientos, en la explicación de los fenómenos naturales, en las divisiones y definiciones referentes a la religión, al derecho y a la cultura entre los antiguos" (Pérez de Urbel 1940: 406).

Al hablar del ser humano, San Isidoro, además de las Sagradas Escrituras, parece seguir el hilemorfismo: "se da el nombre de homo a todo el hombre, esto es, al compuesto de alma y cuerpo (...). Hay un doble hombre: uno interior, que es el alma, y otro exterior, que es el cuerpo. Anima: este nombre viene de los gentiles, que la llamaron así como si dijeran: viento, pues viento en griego es anemos, y dicen que el hombre vive por tomar aire por su boca. Todo esto es abiertamente falso, porque el alma existe mucho antes que se pueda aspirar el aire, ya que vive desde que está en el seno de la madre"12.

Veamos ahora lo que San Isidoro dice del mundo: "El mundo es el cielo, la tierra, el mar y las cosas que hay en ellos; todo obra de Dios, del cual se dice (Io. 1, 10): Et mundus per Eum factus est. (Y el mundo fue hecho por Él)"13; y de su constitución física: "los filósofos llaman átomos a ciertas partes de los cuerpos tan pequeñísimas, que ni se pueden ver ni pueden 
recibir división (en griego tomén), y por eso se llaman átomos (...). El átomo existe en el cuerpo, en el tiempo y en el número. En el cuerpo, como, por ejemplo, la piedra; la divides en partes, las partes vuelves a dividirlas en granos, como son las arenas; de nuevo divides estos granos de arena en polvo minutísimo, hasta llegar a una parte tan pequeña, que ya no puede ser dividida ni cortada. Éste es el átomo en los cuerpos"14.

En cuanto a la Tierra, afirma: "está puesta en la región media del mundo, a manera de centro, a igual distancia de todas las partes del cielo"15. Del orbe dice: "por todas partes le rodea el Océano, cercando sus límites como en círculo. Está dividido en tres partes, de las cuales una es Asia, otra Europa, y la tercera, Africa"16.

San Isidoro toma información de muchas fuentes; pero, no lo hace de un modo histórico: no narra cosas del pasado, sino que trata de dejar plasmado el saber de su tiempo.

\subsection{Teología y ética}

Según san Isidoro, el rey cristiano ideal debe ser justo, prudente, piadoso, clemente y respetuoso con las leyes y la Iglesia, como un guía para todos, como lo fue David. Resumen de las teorías isidorianas es la máxima inspirada en el poeta Horacio: «Rex eris si recte facias; si non facias, non eris». La influencia de esta ideología fue extraordinaria y sentó las bases de la monarquía electiva en el reino visigótico, sobre todo a través de los cánones del concilio IV de Toledo. (Riu, M. et. al. 1975: 133).

Entre sus obras teológicas se cuentan: Del orden de las criaturas, De fide catholica contra judaeos, las Sentencias y el Liber quaestionum adversus judaeos. Tal vez el más importante de éstos sea el de las Sentencias, con el que San Isidoro trata de hacer un manual de doctrina cristiana con textos incluídos de los Santos Padres. Su obra sirvió de ejemplo y modelo durante un milenio. Su idea y su método son nuevos. Trata de explicar los medios que Dios ha dejado a los hombres para su salvación. Sus principales temas son Dios, el mundo y el hombre. Para la dogmática se apoya en San Agustín; para la ética individual y social (pensamiento político), en San Gregorio Magno, especialmente en sus Moralia.

Una de sus obras llamada Synonima, de lamentatione animi peccatricis ("Sinónimos" o "Soliloquios") es de tipo místico.

En las Etimologías, San Isidoro trata de los nombres de Dios, y describe sus atributos uno por uno. A continuación habla de Cristo-Jesús o Hijo de Dios, de sus características y de sus distintos nombres. Del Espíritu Santo dice claramente que "es Dios porque procede del Padre y del Hijo y es consubstancial con ellos"17. Explica las diferencias y relaciones entre las Tres Divinas Personas y los otros nombres del Espíritu Santo. A continuación comenta los órdenes de ángeles según sus oficios. 


\subsection{La Sagrada Escritura}

Comentó casi todos los libros del A.T. (...) expone el sentido típico del Pentateuco, de los Jueces y de los Reyes. (...) ofrece notas introductorias al cánon de la S.E. (...) reseña la vida de los personajes bíblicos más salientes, y (...) [da] una interpretación mística de los números que van saliendo en la Biblia. (Mendoza Ruiz, F. 1984: 120).

San Isidoro tiene varias obras que tratan de la Biblia: De ortu et obitu Patrum, que es de tipo histórico; Proemios que trata sodre cada uno de los libros bíblicos; el "Libro de los números"; las "Alegorías", donde explica el sentido de las parábolas; Mysticorum expositiones sacramentorum, hermenéutica del Antiguo Testamento; De Veteri et Novo Testamento, quaestiones XLI, sobre dificultades que se ven en las escuelas. Sus comentarios son un eslabón muy importante en la cadena de la Sagrada Tradición. Hace interpretaciones tanto alegóricas como literales. Para la Biblia seleccionó con especial cuidado una versión de la Vulgata, pues existían otras versiones con dudosas interpolaciones, les puso el orden hebreo a los libros y les hizo sumarios. Esta versión tuvo influencia fuera de España desde el siglo VIII y en España desde el siglo XII.

\subsection{El Derecho canónico}

La gran empresa canónica de la Iglesia visigoda fue la composición de la colección "Hispana". La "Hispana" parece haberla iniciado san Leandro, siendo su hermano Isidoro quien terminó la puesta a punto de la colección: así surgió la primera recensión de la "Hispana" -la "Isidoriana"-, en una fecha no muy anterior a la muerte de san Isidoro (4-IV-636)". (Orlandis, J. 1976: 276).

San Isidoro fue un gran legislador y se le considera el mejor canonista de su época. Escribió dos libros "Sobre los oficios eclesiásticos", en los que trata histórica y litúrgicamente de los oficios de la Iglesia, fiestas principales, órdenes sagradas, estados y jerarquías del cristianismo. En la Edad Media, pasaron a ser un manual para el clero. Con la "Regla de los monjes", fue colocado a la par de los más grandes legisladores monásticos: San Benito de Nursia y San Basilio. Se basa en San Pacomio, Casiano, San Agustín y San Benito.

San Isidoro influyó también en el Fuero Juzgo y en la nueva codificación del Derecho visigodo.

Son atinadas las siguientes definiciones que presenta en las "Etimologías": "El derecho puede ser natural, civil o de gentes. Derecho natural es el común a todos los pueblos y existe en todas partes, no por ley o constitución, sino por instinto de la naturaleza; como la unión del hombre y la mujer, recepción y educación de los hijos, la misma libertad para todos, común posesión de todas las cosas y derecho a adquirir todo lo que en el cielo, en la tierra y en el mar existe. Además es de derecho natural la restitución de lo prestado o de las cosas depositadas, rechazar la violencia por la violencia; pues estas cosas y otras semejantes nunca son injustas, sino naturales y de equidad"18; y la que presenta de ley, con un trasfondo democrático: "Ley es constitución del pueblo que recibió su sanción de los ancianos, juntamente con el pueblo"19. 


\section{Influencia de San Isidoro mediante sus "Etimologiae"}

Su fama no se redujo a la península Ibérica; atravesó los Pirineos y se abrió paso primeramente en Francia y después, por obra de los monjes irlandeses, sus escritos se difundieron por toda la cristiandad. (Mendoza Ruiz, F. 1984: 121)

Las obras de San Isidoro poseen una gran importancia filológica. Las "Etimologías" tienen términos y expresiones en botánica, zoología, anatomía, arte náutica, pintura, etc., que sólo se encuentran en esa obra y permiten estudiar el bajo latín o latín medieval. Cuando San Isidoro habla del campo y de objetos caseros, menciona muchas palabras que pasaron al romance castellano.

Las "Etimologías" fue la obra preferida de la Edad Media por su claridad, concisión, concreción y hasta completez. Además, puede notarse el aprecio que tuvo la Edad Media por la cultura clásica y que San Isidoro compagina muy bien el cristianismo con las obras literarias y científicas de la Antigüedad. Basta decir que su obra fue la más leída y copiada en la Edad Media, sólo superada por la Biblia ${ }^{20}$. En efecto, pues, San Isidoro, fue uno de los puentes fundamentales entre el saber antiguo y la Edad Media.

\section{Notas}

1. Patrologia latina, LXXXI, 16-17, citado por Pérez de Urbel, J., 1940. "Las letras en la época visigótica". En: Menéndez Pidal (ed.), 400. La mayor parte del estudio que se presenta, está basado en la obra de Pérez de Urbel.

2. Sevilla de Isidoro San. Etimologías, 1.I, c.XXIX, nn. 1 y 2.

3. Ibíd., I. II, c.I, n. 1 .

4. Ibíd., 1. II, c.XXII, n. 1.

5. Sab. 11, 21, citado en S. Isidoro. Op. cit., 1. III, c.IV, n. 1 .

6. Sevilla de Isidoro San. Op. cit., I. III, c.IV, n. 3.

7. Ibíd., 1.III, c.IV, n. 4.

8. Ibíd., l. IV, c.I, nn. 1 y 2.

9. Ibíd., 1. IV, c.XIII, n. 5.

10. Ibíd., 1. II, c.XXIV, n. 1 .

11. Ibíd., l. II, c.XXIV, nn. 3 y 4.

12. Sevilla de Isidoro San. Op. cit., 1. XI, c.1, nn. 4, 6 y 7 .

13. Ibíd., 1. XIII, c.I, n. 1 .

14. Ibíd., 1. XIII, c.II, nn. 1 у 2. 
15.

Ibíd., l. XIV, c.I, n. 1.

16. Ibíd., 1. XIV, c.II, n. 1 .

17. Ibíd., l. VII, c.III, n. 1 .

18. Ibíd., 1. V, c.IV, nn. 1 y 2.

19. Ibíd., l. V, c.X, n. 1 .

20. Véase lo que Menéndez Pidal dice en San Isidoro, Cervantes y otros estudios, pp. 25 y 26: "Por siglos y siglos fué San Isidoro el grito de guerra de la ciencia española: nuestra particular liturgia, más que gótica, más que muzárabe, se llama isidoriana, aunque sus orígenes se remonten hasta los varones apostólicos. Isidoriana se llamó la letra de nuestros códices hasta que los cluniacenses introdujeron la francesa. Con retazos del manto regio de San Isidoro se vistieron y arrearon todos los próceres de nuestra Iglesia. Los libros isidorianos fueron enseñanza asidua en los atrios episcopales y en los monasterios. San Braulio ordenó las Etimologías, Tajón imitó las Sentencias, San Eugenio, los versos; San Ildefonso, el torrente y la copia de sinónimos; San Valerio, las visiones alegóricas; San Julián, todo. A San Isidoro invocaron los sínodos toledanos. Por la fe y por la ciencia de San Isidoro, beatus et lumen, noster Isidorus, como decía Alvaro Cordobés, escribieron y murieron heroicamente los muzárabes andaluces. Arroyuelos derivados de aquella inexhausta fuente son la escuela del abad Spera-in-Deo y el Apologético del abad Sansón. A San Isidoro falsifica en apoyo de su herética tesis el arzobispo Elipando, y con armas de la panoplia de San Isidoro, esgrimidas con dureza de brazo cántabro, trituran y deshacen sus errores nuestros grandes controversistas Heterio y San Beato de Liébana. Los historiadores de la reconquista calcan servilmente las formas del Chronicon isidoriano. Y, finalmente, aquella ciencia española, luz eminente de un siglo bárbaro, esparce sus rayos desde la cumbre del alto Pirineo sobre otro pueblo más inculto todavía; y la semilla isidoriana, cultivada por Alcuino, es árbol frondosísimo en la corte de Carlomagno y provoca allí una especie de renacimiento literario, cuya gloria se ha querido atribuir exclusiva e injustamente a los monjes de las escuelas irlandesas. Y, sin embargo, españoles son la mitad de los que le promueven: Félix de Urgel, el adopcionista; Claudio de Turín, el iconoclasta, y más que todos, y no manchados como los dos primeros con la sombra del error y de la herejía, el insigne poeta Teodulfo, autor del himno de las Palmas, Gloria laus et honor, y el Obispo de Troyes, Prudencio Galindo, adversario valiente del panteísmo de Escoto Erígena. ¿Qué mucho, si extranjeros eran Rabano Mauro y Alcuino, que a cada paso extractan y saquean a San Isidoro; y extranjeros los compiladores del Decreto de Graciano, donde su autoridad se invoca continuamente a par de la de San Agustín y San Jerónimo; y extranjeros los glosadores, que se reparten como preciado botín el abundantísimo gazophylacio de las Etimologías?"

\section{Bibliografía}

Fontaine, Jacques. 1959. Isidore de Seville et la culture classique dans l'Espagne wisigothique. 2 vols. Paris: Ed. Études Augustiniennes.

González Jiménez, Manuel. 1984. "España VI. Historia Antigua y Medieval”. En: Gran Enciclopedia Rialp (GER). Vol. IX. $1^{\text {a }}$ ed., $3^{\text {a }}$ reimp. Madrid: Editorial Rialp.

Isidoro de Sevilla, San. 1951. Etimologías (Texto bilingüe. Trad. del latín por Luis Cortés y Góngora). Madrid: Editorial BAC.

1960. Traité de la nature (Trad. del latín al francés por Jacques Fontaine). Bordeaux: Ed. Féret et Fils. 
Marín, Diego. 1969. La civilización española. EEUU.: Holt, Rinehart and Winston.

Mendoza Ruíz, Fernando. 1984. “Isidoro de Sevilla, San”. En: Gran Enciclopedia Rialp (GER). Vol. XIII, $1^{\text {a }}$ ed., $3^{\text {a }}$ reimp. Madrid: Editorial Rialp.

Menéndez Pidal, Ramón. 1940. Historia de España. Vol. III. Madrid: Espasa-Calpe.

Menéndez y Pelayo, Marcelino. 1959. San Isidoro, Cervantes y otros estudios. Madrid: EspasaCalpe.

Orlandis Rovira, José. 1976. La Iglesia en la España visigótica y medieval. Pamplona: EUNSA. 1981. "Del mundo antiguo al medieval", En: Historia Universal. Pamplona: EUNSA. T III.

1987. "La Antigüedad tardía". En: Montenegro Duque, Angel (coord.), Historia General de España y América. Madrid: Editorial Rialp. T II.

Pérez de Urbel, Justo. 1940. "Las letras en la época visigoda". En: Menéndez Pidal (ed.), $381-431$.

Prampolini, Santiago. 1955. Historia Universal de la Literatura, Vol. III (Trad. del italiano por José Almoine, Carlos Esplá y José López Pérez). Buenos Aires: Editorial UTEHA.

Riquer, Martín de. 1984. "Literaturas medievales de transmisión oral”. En: Riquer, Martín de y José María Valverde (eds.),

Riquer, Martín de y José María Valverde. 1984. Historia de la literatura universal. Vol. II. Barcelona: Editorial Planeta.

Riu, Manuel et al. 1975. Textos comentados de época medieval (siglos V al XII). Barcelona: Editorial Teide. 
